\section{SAT0088 COMPARISON OF THE INITIAL DIAGNOSTIC FINDINGS AND ONSET FACTORS OF RHEUMATOID ARTHRITIS (RA) IN ELDERLY ONSET RA AND ADULT ONSET RA BY MULTICENTER COHORT - ARE THERE ANY DIFFERENCES OF ONSET FACTORS? -}

Keiko Funahashi ${ }^{1}$, Tsukasa Matsubara ${ }^{2}$, Esuke Shono ${ }^{3}$, Motohiro Oribe ${ }^{4}$, Keisuke Hashimoto ${ }^{5}$, Akira Sagawa ${ }^{6}$, Tamami Yoshitama ${ }^{7}$, Takeshi Mitsuka ${ }^{8}$, Tomohiko Yoshida ${ }^{9}$, Atsuko Imai ${ }^{10}$, Nobuaki Miyake ${ }^{11}$, Kazuyasu Ushio ${ }^{12}$, Izumihara Tomomaro ${ }^{13}$, Tsuru Tomomi ${ }^{14}$, Yosuke Nishioka ${ }^{15}$, Shigeto Kiyokawa ${ }^{16}$ Norihiro Nishimoto ${ }^{17} .{ }^{1}$ Matsubara Mayflower Hospital, Clinical research, Kato, Japan; ${ }^{2}$ Matsubara Mayflower Hospital, Rheumatology, Kato, Japan; ${ }^{3}$ Shono Rheumatisum clinic, Fukuoka, Japan; ${ }^{4}$ Oribe Rheumatology clinic, Oita, Japan; ${ }^{5}$ Hashimoto Rheumatology clinic, Kobe, Japan; ${ }^{6}$ Sagawa Akira Rheumatic clinic, Sapporo, Japan; ${ }^{7}$ Yoshitama rheumatology clinic, Kirishima, Japan; ${ }^{8}$ Mitsuka clinic Narashino, Japan: ${ }^{9}$ Yoshida clinic, Setagaya-ku, Japan; ${ }^{10}$ Ichibancho Rheumatology clinic, Matsuyama, Japan; ${ }^{11}$ Miyake clinic, Shizuoka, Japan; ${ }^{12}$ Ushio clinic, Osaka, Japan; ${ }^{13}$ Izumihara rheumatology clinic, Kagoshima, Japan; ${ }^{14}$ PS clinic, Fukuoka, Japan; ${ }^{15}$ Nishioka memorial central clinic, Shima, Japan; ${ }^{16}$ Fujimori clinic, Hachioji, Japan; ${ }^{17}$ Osaka Rheumatology clinic, Osaka, Japan

Background: In recent years, it has been reported that elderly onset RA (EORA) is a pathology different from that adult RA (AORA) ${ }^{1)}$. It has been reported that RA is due to genetic background, and many other factors. However it is not clear whether EORA and AORA share onset factors.

Objectives: We compared the initial diagnostic finding of EORA and AORA patients who were diagnosed by RA specialist at their own hospital. We also compared the presence or absence of the onset factors between EORA and AORA.

Methods: 1185 patients at 18 facilities who were initially diagnosed with RA were included. EORA $(n=398)$ was defined by disease onset at over 60 years and AORA $(n=732)$ was defined by disease onset from16 to 59 years. We compared blood examination, clinical findings, presence of bone erosion, gender, age, and background factors pre-onset (family history, history of smoking/operation, presence of periodontal disease/gynecological diseases/digestive system diseases) between EORA and AORA. Clinical findings were analyzed with Mann-Whitney U-test and frequency of pre-onset history were analyzed by $2 \times 2$ Chi square test.

Results: The average age of EORA and AORA were 72 years and 54 years old. The ratio of female was $75 \%$ in EORA, but $84 \%$ in AORA, a significant difference $(P<0.01)$. The average values of CRP $(\mathrm{ug} / \mathrm{ml})$ were 2.0 in EORA, but it is 1.3 in AORA, significantly lower $(P<0.001)$. Also ESR $(\mathrm{mm} / \mathrm{h})$ and MMP-3 $(\mathrm{ng} / \mathrm{ml})$ of EORA were 46 and 83 , whereas those of AORA were 36 and 29 significant as CRP. On the other hand, TJC, SJC, PaGA and PhGA were not significantly different.

We also compared the prevalence of onset factors between EORA and AORA. There was no clinical significant difference in smoking history and gynecological conditions. The presence rate of stress and family history in AORA were $71 \%$ and $38 \%$, whereas that in EORA was $54 \%$ and $26 \%$, significantly lower $(P<0.001)$. On the other hand, the presence rate of history of gastrointestinal disease, periodontal disease and operation history in AORA were $43 \%, 36 \%$ and $40 \%$, but those in EORA were $49 \%, 46 \%$ and $52 \%$, significantly higher $(\mathrm{P}<0.01)$.

As in previous reports ${ }^{2}$, the ratio of men and the inflammation values in EORA were significantly higher, but there was no difference in SJC, PaGA, and PhGA. This study verified in Japanese EORA as the other reports. There were differences in the presence rate of onset factors between the two groups, while EORA had many external factors such as surgical history, whereas AORA had genetic factors and stress in their backgrounds. Regarding the presence of bone erosion, it was caused by the period from the appearance of the symptoms until the diagnosis and was unrelated to age at onset.

Conclusion: This study suggests that the onset of EORA is more likely to be attributed to external factors than genetic factors.

\section{REFERENCES}

[1] G.Bajocchi et.al, Clin Exp Rheumatol 2000; 18(suppl.20), S49-50

[2] Dejaco.C et.al., Arthitis Care \& Res 2013; 65, 304-308

Disclosure of Interests: Keiko Funahashi Speakers bureau: AYUMI Pharmaceutical Corporation, Eli Lilly Japan K.K., Nichi-lko Pharmaceutical Co., Ltd, Asahi Kasei Pharma Corporation, Tsukasa Matsubara Consultant for: Nichi-lko Pharmaceutical Co., Ltd, Pfizer Japan Inc., Speakers bureau: Astellas Pharma Inc, SEKISUI MEDICAL CO., LTD., UCB Japan Co. Ltd, DAIICHI SANKYO COMPANY Ltd, Bristol-Myers Squibb Company, ONO PHARMACEUTICAL CO., LTD., Mitsubishi Tanabe Pharma Corporation,
Celltrion Healthcare Co.,Ltd, AYUMI Pharmaceutical Corporation, Eisai Co., Ltd, Janssen Pharmaceutical K.K, Pfizer Japan Inc., Asahi Kasei Pharma Corporation, AbbVie GK., Chugai Pharmaceutical Co., Ltd, Eli Lilly Japan K.K., Esuke Shono: None declared, Motohiro Oribe: None declared, Keisuke Hashimoto: None declared, Akira Sagawa Paid instructor for: ONO Pharmaceutical co., Itd, Eli Lilly Japan K.K., Takeda Pharmaceutical Company Limited, AYUMI Pharmaceutical, ISSEI PHARMACEUTICAL CO., LTD., CHUGAI PHARMACEUTICAL CO.,LTD. Asahi Kasei Pharma Corporation, Janssen Pharmaceutical, Tamami Yoshitama: None declared, Takeshi Mitsuka: None declared, Tomohiko Yoshida: None declared, Atsuko Imai: None declared, Nobuaki Miyake: None declared, Kazuyasu Ushio: None declared, Izumihara Tomomaro: None declared, Tsuru Tomomi: None declared, Yosuke Nishioka: None declared, Shigeto Kiyokawa: None declared, Norihiro Nishimoto: None declared

DOI: 10.1136/annrheumdis-2019-eular.2148

\begin{tabular}{|l|l}
\hline SAT0089 & SAFETY AND EFFICACY OF LY3337641, A BRUTON'S \\
& TYROSINE KINASE INHIBITOR IN PATIENTS WITH \\
& RHEUMATOID ARTHRITIS: A RANDOMIZED, DOUBLE- \\
& BLIND, PLACEBO-CONTROLLED, 2-PART PHASE 2 \\
& STUDY
\end{tabular}

Mark C. Genovese ${ }^{1}$, Alberto Spindler ${ }^{2}$, Akira Sagawa ${ }^{3}$, Won Park ${ }^{4}$, Anna Dudek ${ }^{5}$, Alan Kivitz ${ }^{6}$, Jeannie Chao ${ }^{7}$, Lai Shan (Melanie) Chan ${ }^{7}$, William Barchuk, Ajay Nirula ${ }^{7} .{ }^{1}$ Stanford Univ Medical Center, Palo Alto, United States of America; ${ }^{2}$ Centro Medico Privado de Reumatologica, Tucuman, Argentina; ${ }^{3}$ Sagawa Akira Rheumatology Clinic, Sapporo, Japan; ${ }^{4}$ Inha University Hospital, Incheon, Korea, Rep. of (South Korea); ${ }^{5}$ AMED Medical Center, Kalisz, Poland; ${ }^{6}$ Altoona Center for Clinical Research, Duncansville, United States of America; ${ }^{7}$ Eli Lilly and Company, Indianapolis, United States of America

Background: LY3337641 is an irreversible covalent inhibitor of Bruton's tyrosine kinase (BTK), a key signaling molecule in the B-cell-receptor and Fc-receptor pathways and mediator of B-cell- and myeloid-cell-dependent inflammatory arthritis. ${ }^{1,2}$ RA-JUVENATE was a multicenter, randomized, double-blind, placebo-controlled, 2-part Phase 2 trial with long-term extension (LTE) in adult patients (pts) with rheumatoid arthritis (RA).

Objectives: The objective of this analysis is to present the primary results from Part $B$ of the study.

Methods: In Part A, 36 pts with at least mildly active RA were randomized 1:1:1:1 to receive oral LY3337641 5,10 , or $30 \mathrm{mg}$ or placebo (PBO) once daily (QD) for 4 weeks (wks) with the primary objective of safety and tolerability. There were no safety signals to preclude moving to Part B; pts in Part A were not eligible to participate in Part B. In Part B, 250 pts with active moderate to severe RA were randomized 1:1:1:1 receive oral LY3337641 $5(\mathrm{~N}=63), 10(\mathrm{~N}=62)$, or $30 \mathrm{mg}(\mathrm{N}=63)$ or PBO ( $\mathrm{N}=62)$ QD for 12 wks. The primary endpoint of Part $\mathrm{B}$ was the proportion of pts achieving $\geq 20 \%$ improvement in American College of Rheumatology criteria (ACR20) at Wk 12. A logistic regression model was used to compare each LY3337641 dose to PBO for primary and secondary endpoints. Nonresponder imputation was used to impute missing data. After an interim analysis showed a low likelihood of demonstrating significant efficacy at the conclusion of the trial, the sponsor discontinued Part B of the study, including the LTE. Efficacy results (except analysis of low disease activity and remission) included pts who completed through Wk 12 at the time of study discontinuation; safety was results included all pts who received $\geq 1$ dose of study drug.

Results: Of the 250 pts (mean age 51.0 years; $86.4 \%$ female; mean disease duration 11.2 years) randomized in Part B, 189 (75.6\%) completed 12 weeks and 180 entered the LTE (72.0\%); 61 discontinued study treatment in Part B.. The most common reasons for discontinuation were study terminated by sponsor $(27[10.8 \%])$, withdrawal by subject (8 $[3.2 \%])$, adverse event (8 [3.2\%]), and lack of efficacy (4 [1.6\%]). There was no statistically significant difference in the ACR20 response between any treatment group of LY3337641 and PBO at Wk 12 ( $p>0.05$ for all comparisons; Table); a high placebo rate was noted, but no underlying reason was identified in post hoc analyses. There were 5 serious adverse events: 2 in PBO pts (joint dislocation and cholecystitis acute) and 3 in $30-\mathrm{mg}$ pts (foot fracture, multiple injuries, and venous thrombosis). There was 1 death (30-mg pt, multiple injuries after 4-story fall down elevator shaft). There were no safety findings that precluded continuation of the study.

Conclusion: Although there were no safety findings that precluded continuation of the study, the study sponsor determined that the observed benefit-risk profile of LY3337641 in the study did not warrant its continuation. 
Table. Efficacy and safety outcomes at Week 12

\begin{tabular}{|c|c|c|c|c|}
\hline & & & LY333764 & \\
\hline & $\begin{array}{l}\text { Placebo } \\
(\mathrm{N}=62)\end{array}$ & $\begin{array}{l}5-\mathrm{mg} \\
(\mathrm{N}=63)\end{array}$ & $\begin{array}{l}10-\mathrm{mg} \\
(\mathrm{N}=62)\end{array}$ & $\begin{array}{l}30-\mathrm{mg} \\
(\mathrm{N}=63)\end{array}$ \\
\hline Efficacy, $n(\%)$ & & & & \\
\hline ACR & $n=54$ & $n=56$ & $n=52$ & $n=55$ \\
\hline ACR20 & $26(48.1)$ & $31(55.4)$ & $23(44.2)$ & $28(50.9)$ \\
\hline $\begin{array}{l}\text { ACR50a } \\
\text { ACR70 }\end{array}$ & $15(27.8)$ & $14(25.0)$ & $8(15.4)$ & $16(29.1)$ \\
\hline ACR70 & $9(16.7)^{\prime}$ & $5(8.9)$ & $1(1.9)$ & $9(16.4)$ \\
\hline DAS28-CRP & $n=62$ & $n=63$ & $n=62$ & $n=63$ \\
\hline Low disease activityb & $15(24.2)$ & $18(28.6)$ & $11(17.7)$ & $16(25.4)$ \\
\hline Remission ${ }^{6}$ & $11(17.7)$ & $11(17.5)$ & $4(6.5)$ & $14(22.2)$ \\
\hline & $n=44$ & $\mathrm{n}=49$ & $n=47$ & $n=43$ \\
\hline $\begin{array}{l}\text { Change from baseline, observed, } \\
\text { mean (SD) }\end{array}$ & $-1.6(1.4)$ & $-1.6(1.2)$ & $-1.2(1.1)$ & $-1.8(1.5)$ \\
\hline Safety, $n(\%)^{b}$ & & & & \\
\hline Treatment emergent adverse & $31(50.0)$ & $22(34.9)$ & $37(59.7)$ & $34(54.0)$ \\
\hline Serious adverse events & $2(3.2)$ & 0 & 0 & $3(4.8)$ \\
\hline Deaths & 0 & 0 & 0 & $1(1.6)$ \\
\hline Adverse events leading to & $2(3.2)$ & $1(1.6)$ & $3(4.8)$ & $3(4.8)$ \\
\hline & & & & Dthe criteriz \\
\hline
\end{tabular}

\section{REFERENCES}

[1] Di Paolo JA, et al. Nat Chem Biol. 2011;7:41-50

[2] Chakravarty SD, et al. Clin Immunol. 2013;148:66-78.

Disclosure of Interests: Mark C. Genovese Grant/research support from: Sanofi/Genzyme, Genentech/Roche, RPharm, Consultant for: Sanofi/Genzyme, Genentech/Roche, RPharm, Alberto Spindler: None declared, Akira Sagawa Paid instructor for: ONO Pharmaceutical co., Itd, Eli Lilly Japan K.K., Takeda Pharmaceutical Company Limited, AYUMI Pharmaceutical, ISSEI PHARMACEUTICAL CO., LTD., CHUGAI PHARMACEUTICAL CO., LTD., Asahi Kasei Pharma Corporation, Janssen Pharmaceutical, Won Park Consultant for: Celltrion, Inc, Anna Dudek: None declared, Alan Kivitz Shareholder of: Novartis, Consultant for: Abbvie, Janssen, Pfizer, UCB, Genzyme, Sanofi, Regeneron, Boehringer Ingelheim, Sun Pharma Advanced Research, Flexion., Paid instructor for: Celgene, Horizon, Merck, Novartis, Pfizer, Genzyme, Sanofi, Regeneron, Speakers bureau: Celgene, Horizon, Merck and Genetech, Flexion, Jeannie Chao Shareholder of: Eli Lilly and Company, Employee of: Eli Lilly and Company, Lai Shan (Melanie) Chan Shareholder of: Eli Lilly and Company, Employee of: Eli Lilly and Company, William Barchuk Shareholder of: Eli Lilly and Company, Employee of: Eli Lilly and Company, Ajay Nirula Shareholder of: Eli Lilly and Company, Employee of: Eli Lilly and Company

DOI: 10.1136/annrheumdis-2019-eular.2672

\section{SAT0090 GUT MICROBIOTA COMPOSITION IS CONTINGENT WITH DISEASE PHASES IN RHEUMATOID ARTHRITIS}

Elisa Gremese ${ }^{1}$, Francesco Cianci $^{2}$, Stefano Alivernini ${ }^{1}$, Giulia Menchinelli ${ }^{3}$, Anna Laura Fedele $^{4}$, Barbara Tolusso ${ }^{4}$, Brunella Posteraro ${ }^{5}$, Maurizio Sanguinetti ${ }^{5}$. ${ }^{1}$ Fondazione Policlinico Universitario A. Gemelli IRCCS, Università Cattolica del Sacro Cuore, Division of Rheumatology, Rome, Italy, ${ }^{2}$ Università Cattolica del Sacro Cuore, Division of Rheumatology, Rome, Italy, ${ }^{3}$ Fondazione Policlinico Univeristario A. Gemelli IRCCS, Institute of Microbiology, Rome, Italy; ${ }^{4}$ Fondazione Policlinico Universitario A. Gemelli IRCCS, Division of Rheumatology, Rome, Italy, ${ }^{5}$ Fondazione Policlinico Universitario A. Gemelli IRCCS, Università Cattolica del Sacro Cuore, Institute of Microbiology, Rome, Italy

Background: Increasing evidences suggest that alterations in the gut microbiota may contribute to the pathogenesis and influence the clinical outcome of Rheumatoid arthritis (RA).

Objectives: To characterize the gut microbiota composition in RA patients in different disease phases contingently to therapeutic regimens.

Methods: Forty-four RA patients (7 naïve to treatment, $13 \mathrm{MTX}$-IR and 24 in sustained clinical and ultrasound remission under conventional and bDMARD combination therapy, respectively) (age $55.2 \pm 11.4$ years, $79.5 \%$ female and $59.1 \%$ positive for ACPA and/or RF) and 20 age/sex matched healthy controls $(\mathrm{HC})$ were enrolled in the study. At study entry, RA specific data set were collected and dietary habits were recorded using the 14-items Mediterranean Diet Adherence Screener (MeDAS) questionnaire. DNA was extracted from stool samples of each patient, amplified and 16S rRNA gene V3-V4 region was sequenced using an Illumina MiSeq ${ }^{\mathrm{TM}}$ platform. For downstream sequence analysis, a combination of software packages QIIME (v1.9.1) and VSEARCH (v1.1) was used and a biological observation matrix (BIOM) at different taxonomic levels (from phylum to genus) was produced. The BIOM was analysed using the Web-based program MicrobiomeAnalyst. Statistical analyses were performed using the $\mathrm{R}$ phyloseq software package. Differences in the relative abundance of individual bacterial taxa between a priori defined groups were assessed by LEfSe analysis.

Results: Microbiota composition analysis showed that RA patients had a decrease in the gut microbial species richness compared to $H C \quad(p<0.01)$ In particular, the principal coordinate analysis (PCoa) visualization of UniFrac distances and analysis of group similarities (ANOSIM) showed that faecal microbiota composition differs between RA and $\mathrm{HC}(p<0.01)$ confirmed by the LEfSe analysis showing that RA microbiota is enriched of Bacteroidetes and Proteobacteria, whereas $\mathrm{HC}$ were enriched of Verrucomicrobia and Firmicutes. Considering the RA cohort, no significant differences in microbiota composition were found stratifying patients based on autoantibody profile, disease duration and BMI category. However, considering the disease phase, RA patients with active disease (DAS>3.7) showed significant differences in $\alpha$-diversity compared to RA patients in LDA or in sustained clinical and ultrasound remission $(p=0.01)$ with a relative abundance of Haemophilus parainfluenzae in high disease activity patients $(p<0.01)$. A slightly higher $\alpha$-diversity in RA patients with the highest adherence to Mediterranean diet $(p=0.10)$

Conclusion: Despite limited sample size, this study strengthen the concept of significant microbiota differences in RA, contingently with disease phases, compared to $\mathrm{HC}$. The evaluation of microbiota composition in the patients follow-up according to response to therapies is ongoing.

Disclosure of Interests: Elisa Gremese Consultant for: AbbVie, BMS, Celgene, Janssen, Lilly, MSD, Novartis, Sanofi, UCB, Roche, and Pfizer, Speakers bureau: BMS, Speakers bureau: Roche, Speakers bureau: AbbVie, BMS, Celgene, Janssen, Lilly, MSD, Novartis, Sanofi, UCB, Roche, and Pfizer, Francesco Cianci: None declared, Stefano Alivernini Speakers bureau: BMS, Giulia Menchinelli: None declared, Anna Laura Fedele: None declared, Barbara Tolusso: None declared, Brunella Posteraro: None declared, Maurizio Sanguinetti: None declared

DOI: 10.1136/annrheumdis-2019-eular.7980

\section{SAT0091 INCREASED FREQUENCY AND DEFECTIVE SUPPRESIVE CAPACITY OF CD4+CD25+FOXP3+ TREG CELLS IN CHINESE PATIENTS WITH RHEUMATOID ARTHRITIS}

Lan He, Bomiao Ju, Jing Zhang, Nan Hu, LI Zhu, Jian Zheng, Zijing Yin, Zhiming Hao, LV Xiaohong, Dan Pu. First Affiliated Hospital of X'an Jiaotong University, Department of Rheumatology and Immunology, Xi'an, Shaanxi, China

Background: Conflicting evidence exists regarding the proportion and function of $\mathrm{CD}^{+}{ }^{+} \mathrm{CD} 25^{+} \mathrm{Foxp}^{+}$Treg Cells in the peripheral blood (PB) of patients with rheumatoid arthritis $(\mathrm{RA})^{1-6}$

Objectives: The aim of our study was to determine whether Treg cells are defective in Chinese RA patients.

Methods: Levels of $\mathrm{CD}^{+} \mathrm{CD} 25^{+} \mathrm{Foxp}^{+}$Treg cells in the peripheral blood of 224 patients with RA and 38 healthy controls were detected by flow cytometry. The expression of CTLA-4, GITR,Helios and ICOS was also evaluated in order to gain insight into the regulatory function of Treg cells. The production of IFN- $\gamma$, IL17 and IL10 cytokines by Treg cells was also evaluated. Clinical parameters, including DAS28 ESR, the levels of serum Anti-CCP, IgG and IgM were tested. Correlations with Treg cells were systematically analyzed.

Results: Compared to the healthy controls, active RA patients had significantly higher frequency of $\mathrm{CD} 4^{+} \mathrm{CD} 25^{+} \mathrm{Foxp}^{+}$Treg cells $(P<0.01)$. Furthermore, the $\mathrm{CD}^{+}{ }^{+} \mathrm{CD} 25^{+}$Foxp3 ${ }^{+}$Treg cells expressed lower CTLA4 $(P<$ $0.01)$ and produced higher IL17 $(P<0.05)$ and lower IL10 $(P<0.05)$ in RA patients compared with healthy controls in vitro stimulation assay. We also found the proportions of $\mathrm{CD}^{+} \mathrm{CD} 25^{+} \mathrm{Foxp} 3^{+}$Treg cells were significantly higher in Anti-CCP ${ }^{+}$patients compared Anti-CCP-patients $(P<$ 0.01). The frequency of $C D 4^{+} C D 25^{+} F o x p 3^{+}$Treg cells in RA patients was positively correlated with $\operatorname{DAS} 28 \operatorname{ESR}(r=0.135, P=0.043)$, the levels of serum Anti-CCP $(r=0.239, P<0.001), \operatorname{lgG}(r=0.239, P<0.001)$ and $\lg \mathrm{M}(r=0.168, P=0.015)$.

Conclusion: We showed higher frequency of $\mathrm{CD}^{+} \mathrm{CD} 25^{+} \mathrm{Foxp} 3^{+}$Treg cells in PB of RA patients, of which the suppressive capacity was defective.

\section{REFERENCES}

[1] Vitales-Noyola M, Layseca-Espinosa E, Baranda L, et al. Analysis of Sodium Chloride Intake and Treg/Th17 Lymphocytes in Healthy Individuals and Patients with Rheumatoid Arthritis or Systemic Lupus Erythematosus. Journal of immunology research 2018; 2018: 9627806. 